\title{
Macrolide Treatment for Primary Immune Thrombocytopenia
}

\author{
Masashi $\mathrm{OHE}^{1}$, Satoshi HASHINO² \\ ${ }^{1}$ Department of General Medicine, Hokkaido Social Insurance Hospital \\ ${ }^{2}$ Hokkaido University Health Care Center, Sapporo, JAPAN
}

To the Editor,

Macrolides have both immunomodulatory and antibacterial effects. We have already reported 8 cases of primary immune thrombocytopenia (ITP) that showed increased platelet counts (PC) following long-term use of erythromycin (EM) or clarithromycin (CAM) treatment. ${ }^{1-3}$ In our previous reports, the fact that PC increased following macrolide treatment suggested immunomodulatory effects of macrolides. Herein we describe 7 patients whose PC had remained stable with prednisolone (PSL) monotherapy or no therapy, treated with short-term use of macrolides for a common cold.

Case 1, a 66 year-old woman who was Helicobacter pylori (HP)-positive patient, had received unsuccessfully eradication therapy (omeprazole, amoxicillin and CAM) for HP-positive ITP at 61 years old. And PC had remained at the level of $20 \times 10^{9} / \mathrm{L}$. Concretely, 1 month before catching a cold, her PC were $22 \times 10^{9} / \mathrm{L}$. After catching a cold, she was treated with EM at $600 \mathrm{mg} /$ day for 2 weeks. Just before receiving this therapy, her PC were $25 \times 10^{9} / \mathrm{L}$ with PSL at $5 \mathrm{mg} /$ day. After 2 weeks and about 4 weeks, PC indicated $25 \times 10^{9} / \mathrm{L}$ and $24 \times 10^{9} / \mathrm{L}$, respectively.

Case 2, a 69 year-old woman who was HP-positive patient, had not experienced eradication therapy for HPpositive ITP. 3 months before catching a cold, her PC were $90 \times 10^{9} / \mathrm{L}$. After catching a cold, she was treated with CAM at $400 \mathrm{mg} /$ day for 1 week. Just before receiving this therapy, her PC were $84 \times 10^{9} / \mathrm{L}$ with no therapy. After 2 weeks and about 4 weeks, PC indicated $137 \times 10^{9} / \mathrm{L}$ and $87 \times 10^{9} / \mathrm{L}$, respectively.
Case 3, a 24 year-old woman who was HP-negative patient, caught a cold. 1 month before catching a cold, her PC were 96x10\% $/ \mathrm{L}$. She was treated with CAM at 400 $\mathrm{mg} /$ day for 2 weeks. Just before receiving this therapy, her PC were $86 \times 10^{9} / \mathrm{L}$ with PSL at $5 \mathrm{mg}$ /day. After 2 weeks and about 4 weeks, PC indicated $153 \times 10^{9} / \mathrm{L}$ and $102 \times 10^{9} / \mathrm{L}$, respectively.

Case 4, a 75 year-old woman who was HP-negative patient, caught a cold. 1 month before catching a cold, her PC were $41 \times 10^{9} / \mathrm{L}$. She was treated with EM at $600 \mathrm{mg} /$ day for 1 week. Just before receiving this therapy, her PC were $43 \times 10^{9} / \mathrm{L}$ with no therapy. After 1 week and about 4 weeks, PC indicated $97 \times 10^{9} / \mathrm{L}$ and $41 \times 10^{9} / \mathrm{L}$, respectively.

Case 5, an 84 year-old man who was HP-negative patient, caught a cold. 1 month before catching a cold, his PC were 90x10\%/L. He was treated with CAM at 400 $\mathrm{mg} /$ day for 2 weeks. Just before receiving this therapy, his PC were $96 \times 10^{9} / \mathrm{L}$ with PSL at $3 \mathrm{mg} /$ day. After 2 weeks and about 4 weeks, PC indicated $158 \times 10^{9} / \mathrm{L}$ and $102 \times 10^{9} / \mathrm{L}$, respectively.

Case 6, an 88 year-old woman who was HP-negative patient, caught a cold. 3 months before catching a cold, her PC were $36 \times 10^{9} / \mathrm{L}$. She was treated with CAM at $400 \mathrm{mg}$ /day for 1 week. Just before receiving this therapy, her PC were $44 \times 10^{9} / \mathrm{L}$ with no therapy. After 2 weeks and about 4 weeks, PC indicated $184 \times 10^{9} / \mathrm{L}$ and $32 \times 10^{9} / \mathrm{L}$, respectively.

Case 7, a 68 year-old woman who was HP-negative patient, caught a cold. 1 month before catching a cold, her PC were $92 \times 10^{9} / \mathrm{L}$. 


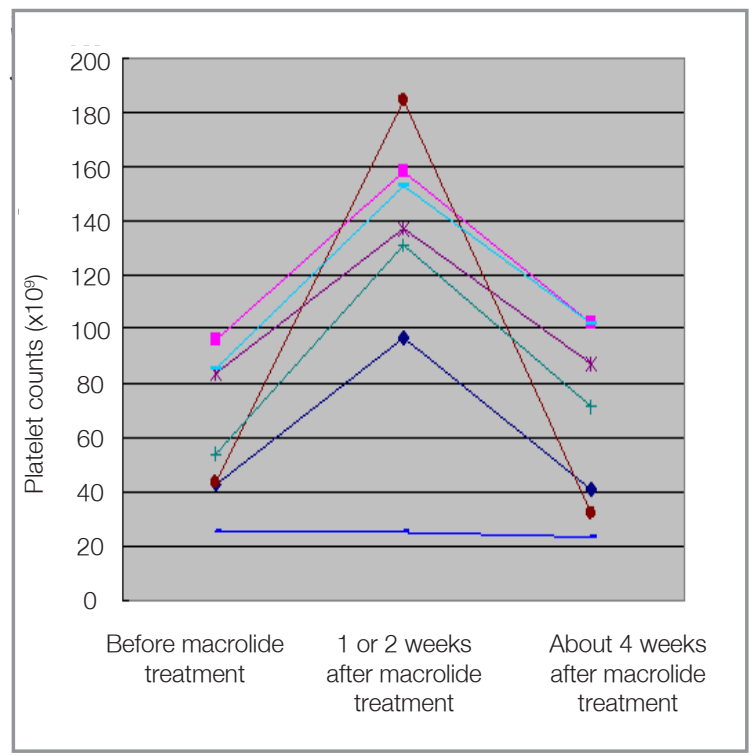

Figure 1. Changes in platelet counts following erythromycin (EM) or clarithromycin (CAM) treatment.

She was treated with EM at $600 \mathrm{mg} /$ day for 1 week. Just before receiving this therapy, her PC were $54 \times 109 / \mathrm{L}$ with no therapy. After 2 weeks and about 4 weeks, PC indicated $131 \times 10^{9} / \mathrm{L}$ and $72 \times 10^{9} / \mathrm{L}$, respectively.

In 6 out of 7 patients treated with macrolides, PC increased after 1 or 2 weeks and decreased after about 4 weeks (Figure 1). And only in 1 patient, namely Case 1, PC did not increase and remained at the level of $20 \times 10^{9} / \mathrm{L}$ (Figure 1). In Case 4, 5, and 6, PC were higher just before taking macrolides than 1 or 3 months before catching a cold. Therefore, PC were thought not to be affected by a cold. As a result, it was suggested that macrolides really increased PC. However, in Case 2, 3, and 7, PC were lower just before taking macrolides than 1 or 3 months before catching a cold. Lower PC just before macrolide treatment and recovered PC 1 or 2 weeks after macrolide treatment might be associated with infection. Recovered PC in Case 2, 3 and 7, might be due to reaction after infection and/or effects of macrolides. After all, at least, in 3 cases, that is, Case 4, 5, and 6 , macrolide treatment was thought to be effective, but temporary. Recent studies have suggested that ITP patients infected with HP can be successfully treated with above-mentioned eradication therapy. It is reported that eradication is only achieved in $15 \%$ of patients with CAM $(1,000$ $\mathrm{mg} /$ day) monotherapy. So the increased PC in Case
2 might be due to a reduction in the quantity of HP and/or a bacteriostatic effect of $\mathrm{CAM},{ }^{4}$ including immunomodulatory effects of macrolides. Because macrolides have steroid-sparing effects via their influence on corticosteroid metabolism, not only immunomodulatory effects but also steroid-sparing effects might increase the PC in Case 3 and 5. Based on these results, ITP patients may benefit from short-term use of macrolides, when they undergo a simple operation such as a tooth extraction or their PC decrease after infection. But repeated short-term or long-term use of macrolides may promote the growth of drug-resistant bacteria, so these macrolides treatment for ITP should not be considered recommended therapies. Otsu et al. reported the effectiveness of a new macrolide which has immunomodulatory effects and no antibacterial effects. ${ }^{5}$ So ITP patients will be able to benefit from this new macrolide treatment without the incidence of drug-resistant bacteria in the future.

\section{REFERENCES}

1. Ohe M, Kohno M. Three cases of idiopathic thrombocytopenic purpura showing an increase in the platelet count following clarithromycin treatment. Rinsho Ketsueki 44: 10441046, 2003.

2. Ohe M, Hashino S. Successful treatment with erythromycin for idiopathic thrombocytopenic purpura. Korean $\mathrm{J}$ Hematol 46: 139-142, 2011.

3. Ohe M, Hashino S. Successful treatment of primary immune thrombocytopenia in aged patients using clarithromycin. J Formos Med Assoc 113: 197-198, 2014.

4. Kuwana M, Ikeda Y. Helicobacter pylori and immune thrombocytopenic purpura: unresolved questions and controversies. Int J Hematol 84: 309-315, 2006.

5. Otsu K, Ishinaga H, Suzuki S, et al. Effects of a novel nonantibiotic macrolide, EM900, on cytokine and mucin gene expression in a human airway epithelial cell line. Pharmacol 88: 321-332, 2011.

\section{Correspondence}

Masashi OHE, M.D.

Hokkaido Social Insurance Hospital

Department of General Medicine

1-8-3-18 Nakanoshima, Toyohira-ku

Sapporo 062-8618 / JAPAN

Tel: $+81-11-831-5151$

Fax: +81-11-821-3851

e-mail: masshi@isis.ocn.ne.jp 